BNL 50762
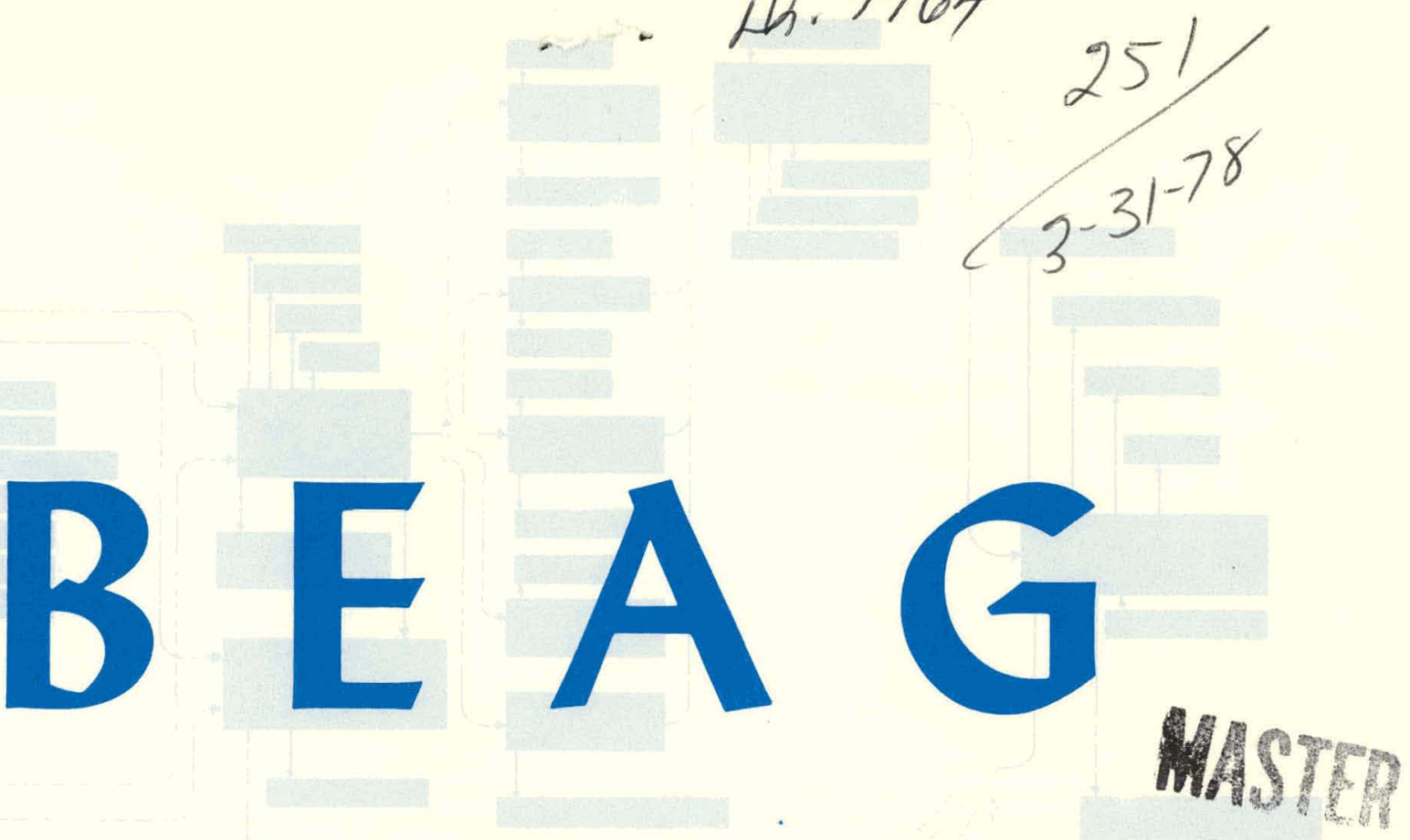

\title{
OUTDOOR SOURCES OF INDOOR AIR POLLUTION
}

\author{
SAMUEL SilberStein
}

NOVEMBER 1, 1977

BIOMEDICAL AND ENVIRONMENTAL ASSESSMENT DIVISION NATIONAL CENTER FOR ANALYSIS OF ENERGY SYSTEMS

\author{
BROOKHAVEN NATIONAL LABORATORY \\ ASSOCIATED UNIVERSITIES, INC. \\ UNDER CONTRACT NO. EY-76-C-02-0016 WITH THE \\ DIVISION OF TECHNOLOGY OVERVIEW/ENVIRONMENT \\ UNITED STATES DEPARTMENT OF ENERGY
}




\section{DISCLAIMER}

This report was prepared as an account of work sponsored by an agency of the United States Government. Neither the United States Government nor any agency Thereof, nor any of their employees, makes any warranty, express or implied, or assumes any legal liability or responsibility for the accuracy, completeness, or usefulness of any information, apparatus, product, or process disclosed, or represents that its use would not infringe privately owned rights. Reference herein to any specific commercial product, process, or service by trade name, trademark, manufacturer, or otherwise does not necessarily constitute or imply its endorsement, recommendation, or favoring by the United States Government or any agency thereof. The views and opinions of authors expressed herein do not necessarily state or reflect those of the United States Government or any agency thereof. 


\section{DISCLAIMER}

Portions of this document may be illegible in electronic image products. Images are produced from the best available original document. 


\title{
OUTDOOR SOURCES OF INDOOR AIR POLLUTION
}

\author{
Samuel Silberstein
}

NOVEMBER 1, 1977

\section{BIOMEDICAL. AND ENVIRONMENTAL ASSESSMENT DIVISION NATIONAL CENTER FOR ANALYSIS OF ENERGY SYSTEMS}

BROOKHAVEN NATIONAL LABORATORY

ASSOCIATED UNIVERSITIES, INC.

UPTON, NEW YORK 11973 
"The Department of Energy (DOE) is the successor to the Energy Research and Development Administration (ERDA) and all references to ERDA herein shall be deemed to refer to DOE."

NOTICE

This report was prepared as an account of work sponsored by the United States Government. Neither the United States nor the United States Department of Energy (DNF), nnr any if their employees, nor any of their contractors, subcontractors, or their employees, makes any warranty, express or implied, or assumes any legal liability or responsibility for the accuracy, completeness or usefulness of any information, apparatus, product or process disclosed, or represents that its use would not infringe privalely owned rights.

Printed in the Unired States of America

Available from

1. National Technical Information Service

U.S. Department of Commerce

5285 Port Royal Road

Springfield, VA 22161

Price: Printed Copy $\$ 4.00 ;$ Microfiche $\$ 3.00$

January 1978

375 copies 


\section{ABSTRACT}

Conservation measures that seal a building, like storm window installation, can significantly reduce its energy requirements. These measures also protect its occupants from air pollutants having outdoor sources but amplify any harmful effects of those generated indoors. Which effect is greater?

It is inadequate to consider outdoor pollution levels constant, so we assume that they follow daily cycles and can thus be well represented by Fourier series'. (Indoor sources can be treated similarly.) It follows that the indoor concentration of any pollutant generated solely outdoors will also follow a daily cycle but its maximum will beth 1 ag behind and be lower than the outdoor maximum to an extent depending in an inverse manner on a building's air exchange (ventilation + infiltration) rate. A simple measure of the daily variation of pollutant concentrations and indoor production rates can be derived from their Fourier series' and used to formulate a test for when these quantities can be assumed constant. Using these Fourier series techniques and an approximation of outdoor pollution peaks by step functions, we obtained the following results: the average daily concentration indoors is the same as outdoors for any pollutant with no indoor sinks if inside and outside air are assumed uniform (that is, well mixed). However, lowering a building's air exchange rate 4-fold will still protect its occupants from outdoor pollution sources, but only if

1) the outdoor peak or variation above its average is much greater than its average, and

2) the peak is short-lived. 
The extent of protection varies in an inverse way with the transiency of the peak; if the peak lasts for $1-2 \frac{1}{2}$ hours, a $2-3$-fold reduction in the peak pollutant level can be expected. By contrast, lowering the air exchange rate the same extent will raise the long-term average concentration due to indoor sources $2 \frac{1}{2}-4-$ fold, and this is probably a more significant effect. 


\section{Outdoor Sources of Indoor Air Pollution}

Rising fuel costs and government tax incentives will probably encourage the use of energy conservation measures. Some of these measures, like the installation of storm windows and improving the quality of building construction, reduce the infiltration of cir (and hence the air exchange rate, v) between the inside and outside of a building. A reduction in infiltration can be expected to raise the indoor levels of pollutants whose origins are primarily indoors, ${ }^{1}$ and to expose a large proportion of the population to these higher concentrations. ${ }^{2}$ Will there be a corresponding reduction in the concentration of pollutants of outdoor origin?

If the outdoor concentration of such a pollutant remains constant, then over the long term its indoor concentration should approach its outdoor concentration. However, indoor concentrations of such pollutants are usually lower than their outdoor concentrations. ${ }^{3,4}$ There are probably two reasons for this: 1. the pollutant, $P$, is removed by the walls or furniture of the house, or in reactions with other pollutants, and/or 2 . the outdoor concentration changes before the indoor concentration has a chance to attain its steady state concentration, which is equal to the outdoor concentration. Thus, to adequately treat the case of outdoor sources of pollution we cannot assume that $\mathrm{P}_{\text {nit. }}$, the outdoor concentration of $\mathrm{P}$, is constant. The equation for the indoor concentration, $\mathrm{p}$, of $\mathrm{P}$ is given by: ${ }^{1}$

$$
p^{\prime}=\frac{d p}{d t}=k-v\left(p-P_{\text {out }}\right)
$$

where $\mathrm{k}=$ rate of formation of $\mathrm{P}$ inside the house/unit volume of the house 
and $\mathrm{P}_{\text {out }}=$ the outdoor concentration of $\mathrm{P}$.

We assume that $P_{\text {out }}$ varies diurnally; that is, it is periodic with a period of 24 hours. In this case it is reasonable to assume that $\mathrm{p}$ is also diurnal.

(We also assume, as we have previously done, ${ }^{1}$ that indoor and outdoor air are uniform and that $\mathrm{v}$ is constant. We will not deal at all with the possibility of indoor reactions of $P$, that is, of sinks.)

If $\mathrm{P}$ is produced solely outdoors then $\mathrm{k}=0$. However, since many pollutants $\left(\mathrm{SO}_{2}\right.$, $\mathrm{NO}_{\mathrm{x}}$, $\mathrm{CO}$ and particulates, for example) are produced both indoors and outdoors, we shall not assume that $k=0$. In fact, with no additional ditficulty, we can solve ( 1 ) when $k$ is not even assumed to be constant, but only diurnal.

To say that $\mathrm{p}, \mathrm{P}_{\text {out }}$ and $\mathrm{k}$ are periodic is to say that they can be represented very well by Fourier series'. Note that for any Fourier series $f=A_{0}+\sum_{1}^{\infty} A_{n} \cos n \theta+\sum_{1}^{\infty} B_{n} \sin n \theta, \bar{f}=$ average of $f=A_{0}$

Thus we may write

$$
P_{\text {out }}=P_{0}+\sum A_{11} \cos n \theta+\sum B_{11} \sin \theta
$$

(3) $\quad \mathrm{k}=\overline{\mathrm{k}}+\sum \mathrm{C}_{\mathrm{n}} \cos \mathrm{n} \theta+\sum \mathrm{D}_{\mathrm{n}} \sin \mathrm{n} \theta$

and

$$
p=\bar{p} \mid \sum a_{n} \cos n 0+\sum b_{n} \sin n 0
$$

where

$$
P_{0}=\overline{P_{\text {out }}, a} \text { constant }
$$

$$
\theta=2 \pi \frac{t-t_{o}}{24 h r}=0.26\left(t-t_{0}\right) / h r
$$

and

$$
t_{0}=\text { some time during the day. }
$$

The, coefficients $A_{n}, B_{n}, C_{n}$ and $D_{n}$ must be defined empirically. 
Substituting (2), (3) and (4) into equation (1) we obtain

(6)

$$
\begin{aligned}
\theta^{\prime}\left(\sum n b_{n} \cos n \theta-\sum n a_{n} \sin n \theta\right)= & \left(\bar{k}-v\left(\bar{p}-p_{o}\right)\right) \\
& +\sum\left(\alpha_{n}-v a_{n}\right) \cos n \theta \\
& +\sum\left(\beta_{n}-v b_{n}\right) \sin n \theta
\end{aligned}
$$

where

$$
\theta^{\prime}=\frac{\pi}{12 \mathrm{hr}} \approx .26 / \mathrm{hr}
$$

$$
\alpha_{n}=c_{n}+v A_{n}
$$

$$
\beta_{n}=D_{n}+v B_{n}
$$

Notice that $k+v P_{\text {out }}=(\bar{k}+v \bar{p})+\sum \alpha_{n} \cos n \theta+\sum \beta_{n} \sin n \theta=$ the rate of addition of pollutant to the house while $v\left(\sum a_{n} \cos n \theta+\sum b_{n} \sin \theta\right)=$ the rate of its removal.

Equating coefficients on both sides of eq. (6) gives us

$$
\begin{aligned}
& \overline{\mathrm{k}}-\mathrm{v}\left(\overline{\mathrm{p}}-\mathrm{p}_{\mathrm{o}}\right)=0 \\
& \theta^{\prime} \mathrm{nb} \mathrm{n}_{\mathrm{n}}=\alpha_{\mathrm{n}}-\mathrm{v} \mathrm{a}_{\mathrm{n}}
\end{aligned}
$$

and

$$
-\theta^{\prime} \mathrm{na}_{\mathrm{n}}=\beta_{\mathrm{n}}-\mathrm{vb} \mathrm{n}_{\mathrm{n}}
$$

from which we get

$$
\overline{\mathrm{p}}=\mathrm{p}_{\mathrm{o}}+\frac{\overline{\mathrm{k}}}{\mathrm{v}}
$$

and the pair, for each $n$, of simultaneous equations

$$
\text { (10a) }
$$

$$
v_{n}+\theta^{\prime} n b_{n}=\alpha_{n}
$$

and

$$
\theta^{\prime} n a_{n}-v b_{n}=-\beta_{n}
$$

Notice that the solution for $\overline{\mathrm{p}}$ in (7) coincides with the steady-state solution for $p$ when $p_{\text {out }}$ and $k$ are constant. ${ }^{1}$ 
A solution to the set of simultaneous equations (8) is given by

$$
a_{n}=\frac{\left|\begin{array}{cc}
\alpha_{n} & \theta^{\prime} n \\
-\beta_{n}-v
\end{array}\right|}{D}=\frac{v \alpha_{n}-\theta^{\prime} n \beta_{n}}{v^{2}+\left(\theta^{\prime}\right)^{2} n^{2}}
$$

(11b)

$$
b_{n}=\underbrace{\left|\begin{array}{cc}
v & \alpha_{n} \\
\theta^{\prime} n & -\beta_{n}
\end{array}\right|}_{D}=\frac{\theta^{\prime} n \alpha_{n}+v \beta_{n}}{v^{2}+\left(\theta^{\prime}\right)^{2} n^{2}}
$$

where

$$
D=\left|\begin{array}{cc}
\bar{v} & H^{\prime} \dot{n} \\
\theta^{\prime} \mathrm{nl} & -v
\end{array}\right|
$$

We will be interested in $\mathrm{P}_{\max }$, the maximum of $\mathrm{p}$, and in how much later it occurs than the maximum of $\mathrm{p}_{\text {out }}$ (the "lag time"). Let $t_{m}=$ the time at which $\mathrm{p}_{\max }$ occurs and $\mathrm{t}_{\mathrm{m}}=$ the time at which $\mathrm{p}_{\text {out }}$ achieves its maximum. The 1atter will probably be known empirically. Then the lag time $=t_{m}-t_{m}$, and $t_{m}$ can be derived simply from $\theta_{\mathrm{m}}=\frac{\pi}{12 \mathrm{hr}}\left(t_{\mathrm{m}}-t_{\mathrm{o}}\right)$ (eq. (5)). $\theta_{\mathrm{m}}$ is a solution of $\mathrm{p}^{\prime}\left(\theta_{\mathrm{m}}\right)=0$ and $\mathrm{p}^{\prime}(\theta)$ is given by the left side of eq. (6).

Unless $p$ is given by a particularly simple Fourier series (for example, $p=\bar{p}+a \cos \theta+b \sin \theta$ ), it will be very difficult to solve for $\theta_{\mathrm{m}}$. For this reason, and because $p$ can be expected to be near its maximum for only brief periods of time, we would like to have another measure of how much we may expect $\mathrm{p}$ to vary over a 24 hour period. Such a measure is provided by $\sigma$, the standard deviation of $\mathrm{p}$ about 1es mean; $\sigma$ ls partlcularly easy lu der lve for a Fourier series. In general 


$$
\sigma^{2}=\sigma^{2}(\mathrm{p})=\overline{\mathrm{p}^{2}}-\overline{\mathrm{p}}^{2}=\frac{-1}{24 \mathrm{hr}} \int_{0}^{24} \mathrm{hr} \mathrm{p}^{2} \mathrm{dt}-\overline{\mathrm{p}}^{2}
$$

Since $\mathrm{p}$ is a Fourier series with a period of $24 \mathrm{hr}$

$$
\frac{1}{24 h r} \int_{0}^{24 h r} p^{2} d t=p^{2}+\frac{1}{2} \Sigma\left(a_{n}^{2}+b_{n}^{2}\right)
$$

so that

$$
\sigma=\frac{1}{\sqrt{2}}\left(\Sigma\left(a_{n}^{2}+b_{n}^{2}\right)\right)^{\frac{1}{2}}
$$

(For example if $p=\bar{p}+a \cos \theta$, then $p_{\max }-\bar{p}=|a|$ but $\sigma$ is only $\frac{|a|}{\sqrt{2}}$ )

We now have a test for determining when we can assume that $p_{\text {out }}$ and $k$ are constant: $P_{\text {out }}$ may be considered to be constant whenever $\frac{1}{\sqrt{2}}\left(\sum A_{n}^{2}+B_{n}^{2}\right)^{\frac{1}{2}}$ is much smaller than $\mathrm{p}_{\mathrm{o}}$. Similarly $\mathrm{k}_{\text {out }}$ may be taken as constant whenever $\frac{1}{\sqrt{2}} \cdot\left(\sum \mathrm{C}_{\mathrm{n}}^{2}+\mathrm{D}_{\mathrm{n}}^{2}\right)^{\frac{1}{2}}$ is much smaller then $\overline{\mathrm{k}}$.

What time does $t_{0}$ represent? $t_{0}$ should be chosen to simply $p_{\text {out }}$ or $k$ as much as possible. For example, if $\mathrm{k}$ refers to the rate of production of a pollutant due to the operation of a heating system, then

$$
k=\bar{k}+D \cos \left(2 \pi \frac{t-t_{o}}{24 h r}\right)
$$

if $t_{0}$ is chosen to be that time of the day when the outside temperature is at its maximum. (If $t_{0}$ is chosen $6 \mathrm{hr}$ earlier then we can replace cos by sin.) For some pollutants it might be possible to choose $t_{0}$ so that $p_{\text {out }}$ varies sinusoidally with $t-t_{0}$ :

$$
\mathrm{p}_{\text {out }}=\mathrm{p}_{\mathrm{o}}+\mathrm{b}_{1} \sin \left(2 \pi \frac{\mathrm{t}-\mathrm{t}_{\mathrm{o}}}{24 \mathrm{hr}}\right)
$$

For other pollutants there might be some time during the day around which $\mathrm{p}_{\text {ont }}$ is distributed symmetrically; for example, if $\mathrm{p}_{\text {out }}$ achieves peaks of comparable size and duration during the morning and afternoon rush hours, $t_{0}$ should be chosen to be either the midpoint between these peaks or 12 hours later. Fig. 1 
illustrates this situation and another, in which there is a single broad peak. If $p_{\text {out }}$ is symmetric about $t_{0}$ (or equivalently about $t_{0}+12 \mathrm{hr}$ ) then all the $\mathrm{B}_{\mathrm{n}}=0$ and only cosine terms appear in $\mathrm{p}_{\text {out }}$. Unfortunately, it would be wholly fortuitous if these special points in time for $k$ and $\mathrm{p}_{\text {out }}$ should coincide; in general, there is no reason that they should. Thus if $t_{0}$ is chosen to simplify $k$, one could not expect any simplification to result in $\mathrm{p}_{\text {out }}$ and vice versa. We will assume below that $\mathrm{p}_{\text {nII }}$ is symmetric because our results will be more clearly illustrated for this case than for the general case, and because many pollutants probably have a symmetric concentration protile (as in Fig. 1 for example).
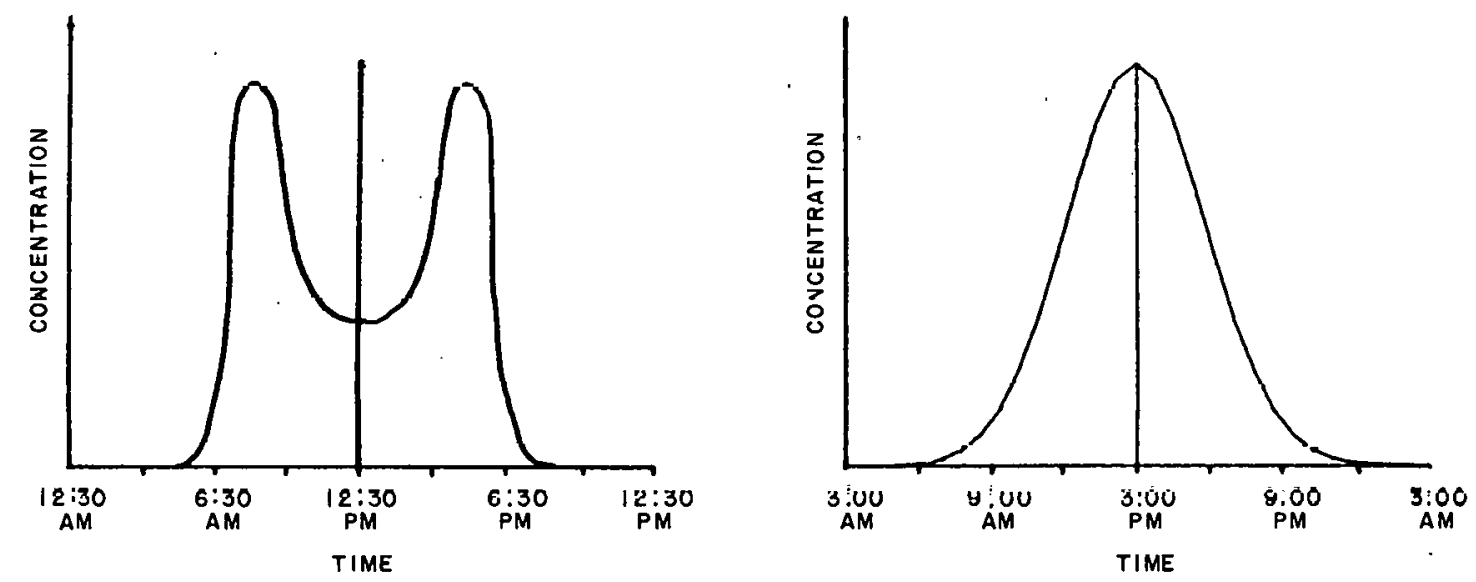

Figure 1. Symmetric pollutant concentration piufiles:

(a) rush hour-like (b) single broad peak. 
Symmetric $\mathrm{p}_{\text {out }}$

Since we are focusing our attention on outdoor sources of indoor

pollution, we may assume that there are no indoor sources, or $k=0$. Then, according to (4), (9) and (11), $\mathrm{p}$ is given by

$$
\mathrm{p}=\mathrm{p}_{\mathrm{o}}+\mathrm{v} \Sigma \frac{\mathrm{A}_{\mathrm{n}}}{\mathrm{v}^{2}+\left(\theta^{\prime}\right)^{2} \mathrm{n}^{2}}\left(\mathrm{v} \cos \mathrm{n} \theta+\theta^{\prime} \mathrm{n} \sin \mathrm{n} \theta\right)
$$

and, by (12), $\sigma$ is given by

$$
\sigma=\frac{v}{\sqrt{2}}\left(\Sigma \frac{A_{n}}{v^{2}+\left(\theta^{\prime}\right)^{2} n^{2}}\right)^{\frac{1}{2}}
$$

Notice that although $\mathrm{p}_{\text {out }}$ is symmetric, $\mathrm{p}$ is not. This is due to the terms of the form $b_{n} \sin n \theta$, each of which modifies the phase of the corresponding cosine term. The total phase difference resulting from $\sum b_{n} \sin n \theta$ is what we previously called the "lag time". As we might have expected, p increasingly resembles $\mathrm{P}_{\text {out }}$ in both magnitude and phase as $\mathrm{v}$ becomes large (i.e. $\left.\lim _{\mathrm{v} \rightarrow \infty} \mathrm{p}=\mathrm{p}_{\mathrm{out}}\right)$. We are more interested, however, in the behavior of $\mathrm{p}$ when $\mathrm{v}$.is smal1.

As $\mathrm{v}$ becomes small compared to $\theta^{\prime}=0.26 / \mathrm{hr}, \mathrm{v} \cos \mathrm{n} \theta$ becomes negligible compared to $\theta^{\prime} n \sin n \theta$, and $v^{2}$ becomes negligible in the denominator terms of (13) and $(14), v^{2}+\left(\theta^{\prime}\right)^{2} n^{2}$. Thus for $v \ll 0.26$ ach

$$
\mathrm{p} \simeq \mathrm{p}_{\mathrm{o}}+\mathrm{v} \sum \frac{\mathrm{A}}{\theta^{\prime} \mathrm{n}} \sin \mathrm{n} \theta \rightarrow \mathrm{p}_{\mathrm{o}} \text { as } \mathrm{v} \rightarrow 0
$$

and

$$
\sigma \simeq \frac{1}{\sqrt{2}} \frac{\mathrm{v}}{\theta^{\prime}}\left(\sum \frac{\mathrm{A}_{\mathrm{n}}^{2}}{\mathrm{n}^{2}}\right)^{\frac{1}{2}} \rightarrow 0 \text { as } \mathrm{v} \rightarrow 0 .
$$

This shows that when $v$ is very much smaller than $\frac{1}{4}$ ach :

1. $\mathrm{p}$ becomes increasingly out of phase with $\mathrm{p}_{\text {out }}$,

2. the oscillations about $\mathrm{P}_{\mathrm{o}}$ become emaller, and

3. $\overline{\mathrm{p}}=\mathrm{p}_{\mathrm{o}}$ is unaffected;

that is, $\mathrm{p}$ becomes more nearly constant. This is shown in Fig. 2, where $\mathrm{p}$ is 
plotted for several values of $v$ and compared with the specific $p_{\text {out }}$ given in the next section.

In Fig. 3 we show an actual profile of the CO concentration inside a house in Hartford, c.t. ${ }^{4,5}$ As the model presented above predicts $\mathrm{p}<\mathrm{p}_{\text {out }}$ when $\mathrm{p}_{\text {out }}$ is near its maximum and $\mathrm{p}>\mathrm{p}_{\text {out }}$ when $\mathrm{p}_{\text {out }}$ is near its minimum. A similar result is reported for $\mathrm{So}_{2} \cdot{ }^{6}$ of ten, however, this behavior is only approximated; while $\mathrm{p}$ continues to be smaller than $\mathrm{p}_{\text {out }}$ for $\mathrm{CO}, \mathrm{SO}_{2}, \mathrm{NO}_{\mathrm{x}}$ and suspended particulate matter when $p_{\text {out }}$ is large, $p$ is ether approximately equal to or a little smaller than $p_{\text {out }}$ when $p_{\text {out }}$ is small and $\bar{p}<p_{\text {out }}{ }^{3,7}$ Some possible explanations for this are that $v$ is not constant throughout the day and neither indoor nor outdoor air is completely uniform, as we have assumed. Instead, there is a pollution gradient between the ultimate pollution source and the interior of the house. Unless measurements are taken just inside and outside an air channel of the house, the average concentration outside would be expected to be greater than the average concentration inside. Another complication is that the house contains sinks for some pollutants 1 ike $\mathrm{SO}_{2}$ and particulates. $^{3}$ If these sinks are located in the cracks of the house, as they may be for particulates, sealing up these cracks may actually remove sinks.

Thus, at best, lowering $\mathrm{v}$ may have some protective value in reducing peaks of concentrations of externally generated pollutants. This will only occur when $\mathrm{p}_{\max }$ or $\sigma$ is very large compared to $\mathrm{p}_{\mathrm{o}}$, and as we shall see below, only when the pollution peak is transient. By contrast, lowering $v$ raises the average concentration of internally generated pollutants ${ }^{1}$ no matter what their particular profiles.

In the next section we obtain some quantitative estimates of the reduction in $\mathrm{p}$ due to lowering $\mathrm{v}$; we then derive conditions for when lowering $\mathrm{v}$ has a maximal beneficial effect. 


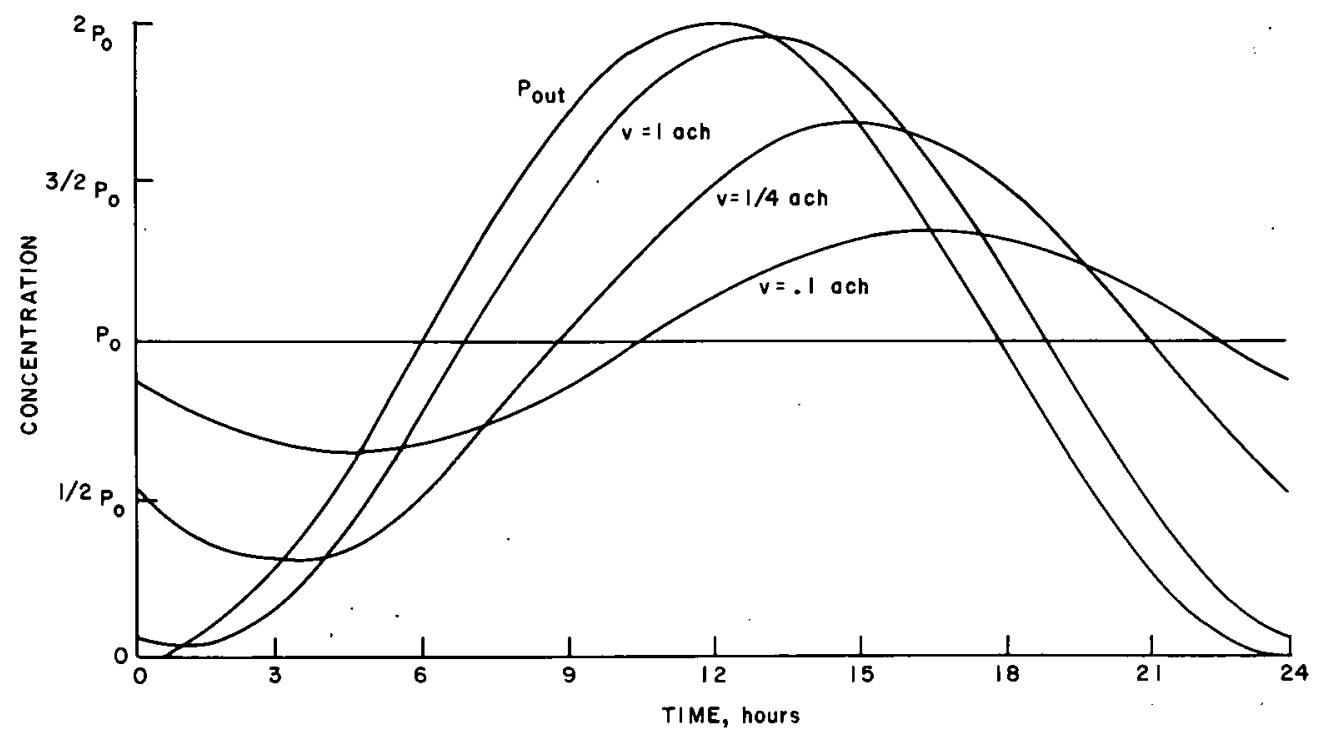

Figure 2. $P_{\text {out }}=P_{o}(1-\cos \theta)$ and $p=P_{o}\left(1-\frac{v}{v^{2}+\left(\theta^{\prime}\right)^{2}} x\right.$ $\left.\left(v \cos \theta+\theta^{\prime} \sin \theta\right)\right)$ for several different $v$. $\left(\theta^{\prime}=\frac{\pi}{12 \mathrm{hr}}\right.$ and $\left.\theta=\theta^{\prime} \mathrm{t}\right)$.

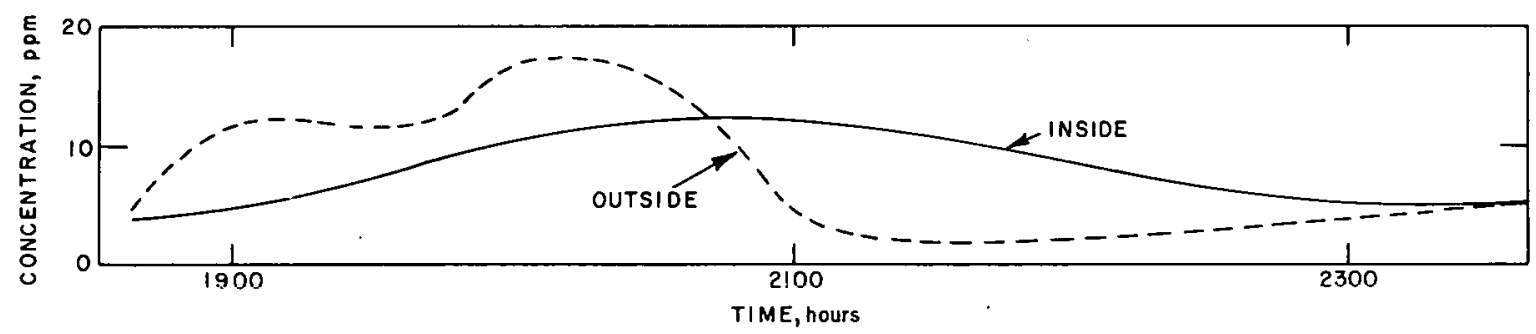

Figure 3. Carbon monoxide concentrations for house in Hartford, Connecticut; September 22, 1969.5

(copied from ref. 4).

$\mathrm{P}_{\text {out }}$ is sinusoidal

Actually, it will be more convenient to represent $p_{\text {out }}$ as

$$
\mathrm{p}_{\text {out }}=\mathrm{p}_{\mathrm{o}}-\mathrm{A} \cos \theta, \mathrm{A}>0
$$

than as $p_{0}+$ Asin $\theta ;$ the only difference in these profiles is a phase difference of $6 \mathrm{hr}$; all the important parameters like the lag time, $\mathrm{p}_{\max }$ and $\sigma$ are

\section{identica1.}

We choose $A$ as large as possible compared to $\mathrm{p}_{\mathrm{O}}$, so that lowering $\mathrm{v}$ will have the greatest possible effect. Since $\mathrm{p}_{\text {out }} \geqq \mathrm{p}_{\mathrm{o}}-\mathrm{A} \geqq 0, \mathrm{~A}=\mathrm{p}_{\mathrm{o}} \cdot$ (17) now becomes 


$$
\mathrm{p}_{\text {out }}=\mathrm{p}_{\mathrm{o}}(1-\cos \theta)
$$

and the solution (13) is given by

$$
\mathrm{p}=\mathrm{p}_{\mathrm{o}}-\mathrm{p}_{\mathrm{o}} \frac{\mathrm{v}}{\mathrm{v}^{2}+\left(\theta^{\prime}\right)^{2}}\left(\mathrm{v} \cos \theta+\theta^{\prime} \sin \theta\right)
$$

We plot $\frac{p_{\text {out }}}{p_{0}}$, and $\frac{p}{p_{0}}$ for several values of $v$, in Fig. 3. We also have, from (14),

$$
\sigma=\frac{p_{o} v}{\sqrt{2}\left(v^{2}+\left(\theta^{\prime}\right)^{2}\right)^{\frac{1}{2}}}
$$

We can now calculate $\mathrm{p}_{\max }$ and the lag time. Let $\mathrm{t}_{\mathrm{o}}=0$. Then $\mathrm{p}_{\text {out }}$ achieves its maximum at

$$
\mathrm{t}_{\mathrm{m}}^{\prime}=12 \mathrm{hr}
$$

We need $\mathrm{p}^{\prime}$ :

$$
\mathrm{p}^{\prime}=\frac{\mathrm{p}_{\mathrm{o}} \mathrm{v} \theta^{\prime}}{\mathrm{v}^{2}+\left(\theta^{\prime}\right)^{2}}\left(\mathrm{v} \sin \theta-\theta^{\prime} \cos \theta\right)
$$

Setting $\mathrm{p}^{\prime}=0$ we obtain $\theta_{\mathrm{m}}$ :

$$
\begin{aligned}
& \operatorname{vsin} \theta_{m}=\theta^{\prime} \cos \theta_{m} \\
& \tan \theta_{m}-\frac{\theta^{\prime}}{v} \\
& \dot{\theta}_{m}=\theta^{\prime} t_{m}=\arctan \frac{0^{\prime}}{v}
\end{aligned}
$$

There are two solutions to (21); $t_{m}$ is greater of these; the other solution, occuring 12 hours earlier, is the time when $p$ achieves its minimum. Choosing the correct solution of (21), we get

$$
\text { "lag time" }=t_{m}-12 \mathrm{hr}=\frac{1}{\theta^{\prime}} \operatorname{arc} \tan \left(\frac{\theta^{\prime}}{\mathrm{v}}\right)-12 \mathrm{hr}
$$

Substituting (21) into (19) we obtain

$$
\mathrm{p}_{\max }=\mathrm{p}_{0}+\mathrm{p}_{\mathrm{o}} \frac{\mathrm{v}}{\left(\mathrm{v}^{2}+\left(\theta^{\prime}\right)^{2}\right)^{\frac{3}{2}}}
$$

Comparing (20) and (23) we see that 


$$
\sigma=\frac{1}{\sqrt{2}}\left(\mathrm{p}_{\max }-\mathrm{p}_{\mathrm{o}}\right) \simeq .7\left(\mathrm{p}_{\max }-\mathrm{p}_{\mathrm{o}}\right)
$$

As an approximation, since $\mathrm{p}>\mathrm{p}_{\mathrm{o}}$ about as of ten as $\mathrm{p}<\mathrm{p}_{\mathrm{o}}$, we may consider that. $\mathrm{p}$ has an effective concentration of $\mathrm{p}_{\mathrm{o}}+\sigma$, for half of each day and of $\mathrm{p}_{\mathrm{o}}-\sigma$ for the other half. In Table I we calculate lag times, $\frac{\mathrm{p}}{\mathrm{p}_{\mathrm{o}}}$, and $\frac{\sigma}{\mathrm{p}_{\mathrm{o}}}$ for various values of $v$; we include the extreme cases $v=0$ and $v=\infty$. As. expected, all the parameters approach their values for these extreme cases as $\mathrm{v}$ becomes very small or large, repectively. Note that for $v=\frac{1}{4} \mathrm{ach}$, which is very close to $\theta^{\prime}$, the lag time is midway between its two extreme values; this is also as expected from the discussion in the last section.

\section{Table I}

The effects of $v$ on outdoor generated indoor air pollution when $\mathrm{p}_{\text {out }}=\mathrm{p}_{\mathrm{o}}(1-\cos \theta)$

$v(a c h) \quad \operatorname{lag}$ time $(h r) \quad \frac{p_{\max }}{p_{0}} \cdot \frac{\sigma}{p_{0}}$

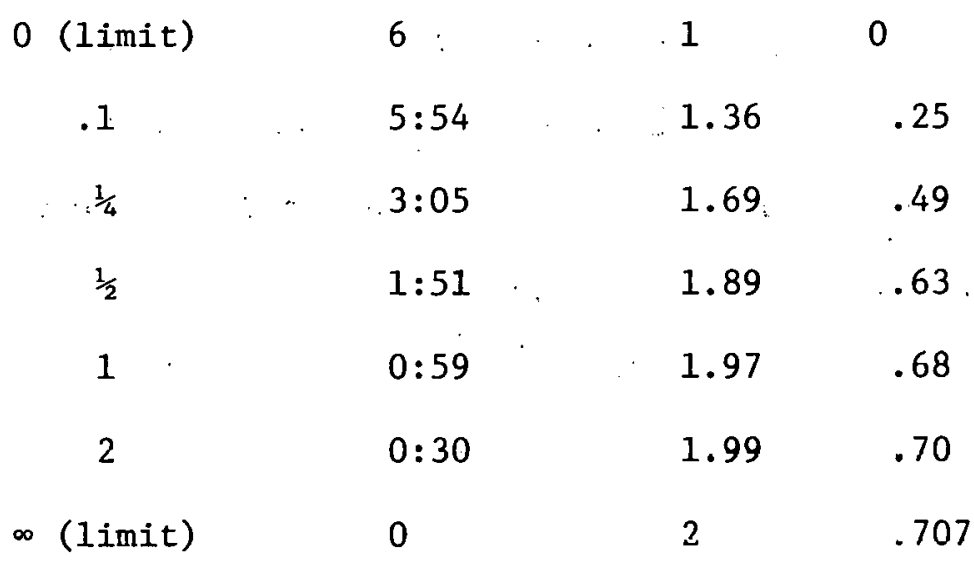


What are the effects of lowering $v$ from 1 to $\frac{1}{4} \mathrm{ach}$, for example? For $\mathrm{v}=1 \mathrm{ach}, \mathrm{p}$ achieves its maximum $1 \mathrm{hr}$ later than $\mathrm{p}_{\text {out }}$ does, and $\mathrm{p}_{\max }=1.97 \mathrm{p}_{\mathrm{o}}$. For the half of the day we are interested in (i.e. when $p>p_{o}$ ), $p \simeq 1.68 p_{0}$ For $v=\frac{1}{4}$ ach, $\mathrm{p}$ does not achieve its maximum until $3 \mathrm{hr}$ later than $\mathrm{p}_{\text {out }}$ does, $\mathrm{p}_{\max }=1.69 \mathrm{p}_{\mathrm{o}}$ and for the interesting half of the day $\mathrm{p} \simeq 1.49 \mathrm{p}_{\mathrm{o}} \cdot$ Thus, $\mathrm{p}_{\max }$ is reduced 14\%, and for half of each day, the effective concentration is reduced by $12 \%$. $\overline{\mathrm{p}}$, of course, remains unchanged at $\mathrm{p}_{\mathrm{o}} \cdot$ In contrast, if $\mathrm{P}$ were produced exclusively indoors (at a production rate independent of $v^{1}$ ), then for the same reduction of $v$, its average concentration would have increased $300 \%$ ! (150\% if heating systems produce $P$ because they can operate less if $V$ is reduced. ${ }^{1}$ ) We don't wish to give the impression that this result is a general one. The shape of $p_{\text {out }}$ is much more important for an analysis of $p$ than the shape of $k$. The reason for this is that since $\bar{p}$ changes when it is due to $k$, but does not when it is due to $\mathrm{p}_{\text {out }}$, any oscillations about average values are more important in the latter case. For example, in the profile we analyzed in detail above, an examination of Table I will reveal that the orders of maynilule of $\mu_{0}, p_{\text {out, }}$ max $-\mathrm{p}_{\mathrm{o}}$ and $\sigma$ are similar. Fig. 2 shows that the breadth of the peak in $p_{\text {out }}$ (the time it takes for $p_{\text {out }}$ to rise from $\frac{1}{2}$ of its peak he1ght above average, $\frac{3}{2} \mathrm{p}_{\sigma}$ through its peak, $2 \mathrm{p}_{0}$, and back down to $\frac{3}{2} \mathrm{p}_{0}$ ) is 8 hours. We will show in the next section that if we increase $p_{\text {out, }}$ max relative to $\mathrm{P}_{\mathrm{o}}$ and decrease the breadth of the peak sufficiently, then lowering $\mathrm{v}$ may be beneflclal in protecting against high outdoor pollution levels. 


\section{Health Benefits of Lowering $v$}

In order to achieve a significant reduction in $\mathrm{p}_{\max }$ when $\mathrm{v}$ is lowered, $\mathrm{P}_{\text {out, } \max }-\mathrm{p}_{\mathrm{o}}$ must be much larger than $\mathrm{p}_{\mathrm{o}}$; otherwise even the complete elimination of the peak at $t_{m}$ will have little effect on $p_{\max }$ since $p_{\max }-p_{0} \leq p_{o u t, ~} \max -p_{o}$. In addition, the breadth of the peak at $t_{m}$ must be small. We can see this as follows.

If there are no indoor sources of $P$, then the essential features of $p$ can be derived from equation (1):

1. $\mathrm{p}$ increases $\left(\mathrm{p}^{\prime}>0\right)$ whenever $\mathrm{p}<\mathrm{p}_{\text {out }}$.

2. $\mathrm{p}$ reaches its maximum when $\mathrm{p}=\mathrm{p}_{\text {out }}$, and

3. $\mathrm{p}$ decreases $\left(\mathrm{p}^{\prime}<0\right)$ whenever $\mathrm{p}>\mathrm{p}_{\text {uul }}$

The actual co profile in Fig. 3 displays these features, as do the profiles in Fig. 2 and 4 .

Now suppose that $p_{\text {out }}$ has a sharp peak around time $t_{m}$. (F ig. 4 ). If $v$ is small, $\mathrm{p}$ will not increase very much before it intersects $\mathrm{p}_{\text {out }}$ during the descent of the letter from its maximum, after which $p$ must decrease also. (Fig. 4 illustrates the behavior of $\mathrm{p}$ for relatively small and large $v_{\text {.) }}$

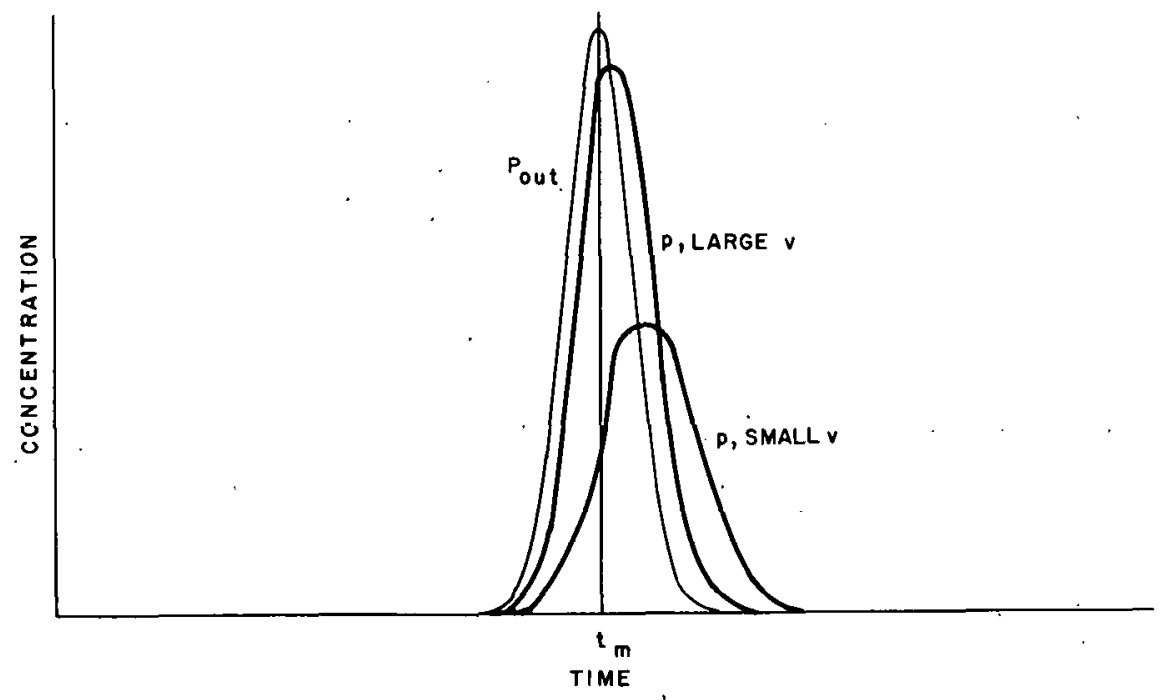

Figure 4. Pollutant concentration profile with a single sharp peak at time $t_{m}$. 

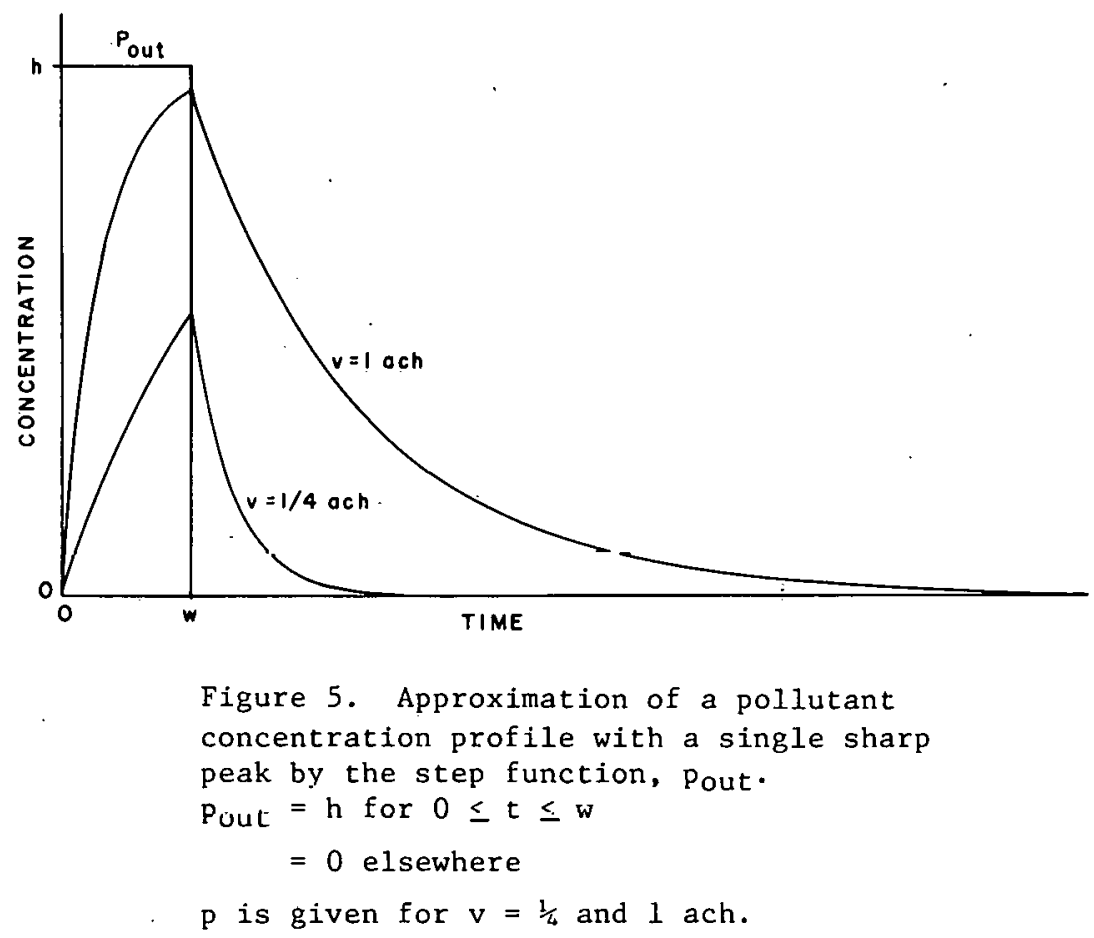

How small must the breadth of the peak be in order for the outdoor concentration of pollutant to be reduced significantly?

Let us approximate any peak of breadth $w$ and height $h$ by the step function (shown in Fig. 5):

$$
\begin{aligned}
& \mathrm{P}_{\text {out }}=\mathrm{h} \text { for } 0 \leq t \leq \mathrm{w} \\
& \mathrm{p}_{\text {out }}=0 \text { elsewhere }
\end{aligned}
$$

Let us further assume that at time $t=0 \quad p=0$. Then, we know that $\mathrm{p}_{\mathrm{v}}$ (we write $\mathrm{p}=\mathrm{p}_{\mathrm{v}}$ to emphasize its dependence on $\mathrm{v}$ ) achieves its maximum at time $w$ and that

$$
\mathrm{P}_{\mathrm{v}} \max =\mathrm{h}\left(1-\mathrm{e}^{-\mathrm{vw}}\right)
$$

In Table II we show how large $w$ can be so that $p$ remains smaller than certain multiples of $h$, for $v=\frac{1}{4}$ ach. 
Table II

Maximum breadth of peak in order that

$\mathrm{p} \leq \alpha \mathrm{h}$ when $\mathrm{v}=\frac{1}{4} \mathrm{ach}$

$\begin{array}{lc}\alpha & \text { maximum w (hr) } \\ .1 & 0: 25 \\ .25 & 1: 09 \\ .5 & 2: 46\end{array}$

How much protection can we get by lowering $v$ from 1 to $\frac{1}{4}$ ach? We take the ratios, $R$ of $p_{1}$, max to $p_{\frac{1}{4}}$, max

$$
R=\frac{p_{1}, \max }{p_{\frac{1}{4}}, \max }=\frac{1-e^{-w h r}}{1-e^{-\frac{w}{4} h r}}
$$

Now for

$0<\mathrm{w} \leq 0: 50 \mathrm{hr}$

$3 \leq \mathrm{R}<4$,

for

$0: 50 \mathrm{hr}<\mathrm{w} \leq 2: 26 \mathrm{hr}, \quad 2 \leq \mathrm{R}<3$,

and for

$2: 26 \mathrm{hr}<\mathrm{w}<24 \mathrm{hr}$,

$1<\mathrm{R}<2$.

Thus we see that as long as the peak height is less than $2 \frac{1}{2}$ hours, there will be at least a two-fold reduction of $\mathrm{p}$ caused by lowering $\mathrm{v}$ from 1 to $\frac{1}{4} \mathrm{ach}$. Pollutants that are most likely to exhibit this kind of transient behavior, that is, attain short lived peaks that are enormous relative to their average concentrations, are automobile emissions during rush hours traftic: 
Lowering $v$ 4-fold may afford some protection against pollutants originating outdoors by reducing their peak concentrations indoors approximately in half. At the same, however, long-term average indoor concentrations of practically all internally generated pollutants will be raised $2.5-4-$ fold. It seems likely that the latter is the more important effect.

\section{$\underline{\text { References }}$}

1. Silberstein, S. Energy Conservation and Indoor Air Pollution, in prep.

2. Silberstein, S. Exposure to Indoor Pollution, in prep.

3. Geomet, Inc. The Status of Indoor Air Pollution Research, Gaithersburg, Md. (1976).

4. Benson, F. B., Henderson, J. J. and Caldwe11, D. E. Indoor-Outdoor Air Pollution Relationships: a Literature Review. U.S. Environmental Protection Agency, Research Triangle Park, N. C. (1972).

5. Yocom,J. E., Clink, W. L. and Cote, W. A. T.ndonr/Outdoor Air Quality Relationships. J, Air Pol1. Contr. Assoc. 21, 251-9 (1970).

6. Arthur D. Little, Inc. Field Study of Air Qual1ty in Air Conditioned Spaces, RP-86. Cambridge, Mass. (1970).

7. Andersen, I. Relationships Between Outdoor and Indoor Air Pollution. Atmos. Env. 6, 275-8 (1972).

\section{ACKNOWLEDGMFNT}

I am grateful to Samuel C. Morris for his helpful discussinns and review of this paper. 